\title{
Effects of enriched-potassium diet on cardiorespiratory outcomes in experimental non-ischemic chronic heart failure
}

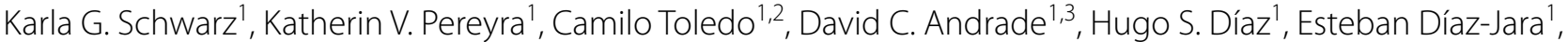 \\ Domiziana Ortolani ${ }^{1}$, Angélica Rios-Gallardo ${ }^{1,2}$, Paulina Arias ${ }^{1}$, Alexandra Las Heras ${ }^{1}$, Ignacio Vera ${ }^{1}$, \\ Fernando C. Ortiz ${ }^{4}$, Nibaldo C. Inestrosa ${ }^{2,6}$, Carlos P. Vio ${ }^{5,6}$ and Rodrigo Del Rio ${ }^{1,2,6^{*}}$ (1)
}

\begin{abstract}
Background: Chronic heart failure (CHF) is a global health problem. Increased sympathetic outflow, cardiac arrhythmogenesis and irregular breathing patterns have all been associated with poor outcomes in CHF. Several studies showed that activation of the renin-angiotensin system (RAS) play a key role in CHF pathophysiology. Interestingly, potassium $\left(\mathrm{K}^{+}\right)$supplemented diets showed promising results in normalizing RAS axis and autonomic dysfunction in vascular diseases, lowering cardiovascular risk. Whether subtle increases in dietary $\mathrm{K}^{+}$consumption may exert similar effects in CHF has not been previously tested. Accordingly, we aimed to evaluate the effects of dietary $\mathrm{K}^{+}$supplementation on cardiorespiratory alterations in rats with CHF.
\end{abstract}

Methods: Adult male Sprague-Dawley rats underwent volume overload to induce non-ischemic CHF. Animals were randomly allocated to normal chow diet (CHF group) or supplemented $\mathrm{K}^{+}$diet (CHF+K+ group) for 6 weeks. Cardiac arrhythmogenesis, sympathetic outflow, baroreflex sensitivity, breathing disorders, chemoreflex function, respiratorycardiovascular coupling and cardiac function were evaluated.

Results: Compared to normal chow diet, $\mathrm{K}^{+}$supplemented diet in CHF significantly reduced arrhythmia incidence $\left(67.8 \pm 15.1\right.$ vs. $31.0 \pm 3.7$ events/hour, CHF vs. $\left.C H F+K^{+}\right)$, decreased cardiac sympathetic tone ( $\triangle$ HR to propranolol: $-97.4 \pm 9.4$ vs. $-60.8 \pm 8.3 \mathrm{bpm}, \mathrm{CHF}$ vs. $\left(\mathrm{HF}+\mathrm{K}^{+}\right.$), restored baroreflex function and attenuated irregular breathing patterns. Additionally, supplementation of the diet with $\mathrm{K}^{+}$restores normal central respiratory chemoreflex drive and abrogates pathological cardio-respiratory coupling in CHF rats being the outcome an improved cardiac function.

Conclusion: Our findings support that dietary $\mathrm{K}^{+}$supplementation in non-ischemic CHF alleviate cardiorespiratory dysfunction.

Keywords: Heart failure, Potassium supplemented diet, Autonomic imbalance, Breathing disorders, Chemoreflex function

*Correspondence: rdelrio@bio.puc.cl

1 Laboratory of Cardiorespiratory Control, Department of Physiology, Pontificia Universidad Católica de Chile, Santiago, Chile

Full list of author information is available at the end of the article

\section{Background}

Chronic heart failure (CHF) affecting 26 million people worldwide [1], represent the leading cause of hospital admissions in people over 65 years old [2]. One form of CHF is due to the loss of ventricular mass following ischemic events which trigger cardiac systolic dysfunction $(<40$ ejection fraction, EF). Contrarily, non-ischemic original author(s) and the source, provide a link to the Creative Commons licence, and indicate if changes were made. The images or other third party material in this article are included in the article's Creative Commons licence, unless indicated otherwise in a credit line to the material. If material is not included in the article's Creative Commons licence and your intended use is not permitted by statutory regulation or exceeds the permitted use, you will need to obtain permission directly from the copyright holder. To view a copy of this licence, visit http://creativecommons.org/licenses/by/4.0/. The Creative Commons Public Domain Dedication waiver (http://creativeco mmons.org/publicdomain/zero/1.0/) applies to the data made available in this article, unless otherwise stated in a credit line to the data. 
CHF is characterized by normal EFs and marked impairments in cardiac diastolic function [3]. Notably, the prevalence of non-ischemic $\mathrm{CHF}$ is increasing in the worldwide population and mortality remains high. The later evidence the lack of effective means to help in the management of non-ischemic heart disease [3]. Despite the progress in therapeutic strategies, non-ischemic CHF prevalence is increasing over time and mortality remains high due to the greater number of both elderly people and comorbidities associated with CHF (i.e. hypertension, obesity, and coronary artery disease) $[3,4]$. Therefore, novel treatments for non-ischemic CHF have become a global health priority [1]. Pathophysiological hallmarks of CHF patients include autonomic dysfunction characterized by cardiac sympathetic overactivity and parasympathetic withdrawal $[5,6]$, alterations in heart rate variability, and reduction of cardiac baroreflex sensitivity [7]. Importantly, enhanced cardiac sympathetic drive is a potent trigger for cardiac arrhythmogenesis which may lead to increase the risk of decompensation and mortality in CHF [8]. Furthermore, almost $50 \%$ of CHF patients display alterations in resting breathing patterns (i.e. apneas, hypopneas, periodic breathing) [9] that add more stress to the heart through chemoreflex activation of the sympathetic nervous system. Conversely, increased chemoreflex activation also promotes the development of altered breathing patterns then creating a vicious cycle that compromises further deterioration in cardiac function [10].

Several molecular mechanisms have been pointed out to contribute to CHF progression. However, a growing body of evidence suggests that chronic activation of the renin-angiotensin-system (RAS) is closely related with CHF progression [11]. Indeed, Angiotensin II (AngII)induced reactive oxygen species (ROS) production in the central nervous systems enhances sympathetic outflow in CHF $[11,12]$. Furthermore, increases in systemic and brain AngII levels in CHF has also been reported. AngIIderived ROS are mainly originated through activation of nicotinamide adenine dinucleotide phosphate (NADPH) oxidase via AngII receptor type I $\left(\mathrm{AT}_{1} \mathrm{R}\right)[13,14]$. Importantly, previous studies shown that non-ischemic $\mathrm{CHF}$ rats display enhanced NADPH oxidase activation and superoxide production in the rostral ventrolateral medulla (RVLM), a major site for sympathetic regulation [15-17]. Therefore, strategies intended to reduce AngIIderived ROS and their well-known pathophysiological consequences in CHF may contribute to the control of cardiovascular and respiratory alterations.

Potassium $\left(\mathrm{K}^{+}\right)$supplemented or enriched diets have been proposed as a feasible complementary clinical indication to prevent major detrimental cardiovascular events, particularly for the management of arterial blood pressure in human and experimental hypertension [1821]. Indeed, $\mathrm{K}^{+}$intake prevents the induction of RAS, improves sodium excretion and blood pressure regulation by modulating renal sympathetic activity [22-24]. Furthermore, a cardioprotective effect of dietary $\mathrm{K}^{+}$has also been described since subtle increases in $\mathrm{K}^{+}$inhibits NADPH oxidase activity and reduced ROS formation [25, 26]. This evidence supports that dietary $\mathrm{K}^{+}$supplementation may have beneficial physiological effects in disease states characterized by RAS activation and sympathoexcitation [27]. Importantly, western diets are characterized by $\mathrm{K}^{+}$deficiency and excessive sodium $\left(\mathrm{Na}^{+}\right)$intake and have been largely linked to the development/aggravation of cardiovascular diseases [28-30].

Together, evidence support the notion that dietary $\mathrm{K}^{+}$supplementation may offer benefit in the setting of $\mathrm{CHF}$; however, to our knowledge there are no comprehensive studies showing if increases in daily $\mathrm{K}^{+}$intake may help improving cardiovascular and respiratory function in CHF. Accordingly, we aimed to determine the effect of dietary $\mathrm{K}^{+}$supplementation on sympathetic and parasympathetic outflow, baroreflex sensitivity, cardiac arrhythmogenesis, breathing disorders, chemoreflex function, respiratory-cardiovascular coupling and cardiac function in experimental non-ischemic CHF.

\section{Methods}

\section{Ethical considerations and animals}

Experiments were performed on 15 male Sprague-Dawley rats housed in a controlled temperature environment with light/dark cycle of $12 \mathrm{~h}$ and water-food ad libitum (see Additional file 1: Fig. S1 for experimental timeline). The protocol was approved by the Ethical-Scientific Committee of the Facultad de Ciencias Biológicas, Pontificia Universidad Católica de Chile (Protocol ID 170710022), and was conducted in accordance with the National Institutes of Health (NIH) Guide for the Care and Use of Laboratory Animals. All animals were humanely euthanized with an overdose of sodium pentobarbital $\left(100 \mathrm{mg} \mathrm{kg}^{-1}\right.$ ip).

\section{Experimental non-ischemic CHF}

Non-ischemic chronic heart failure (CHF) was produced by the surgical creation of an arteriovenous shunt between the abdominal aorta and the cava vein to induced chronic volume overload [16, 17, 31-34]. Under anesthesia (induction with $5 \%$ of isoflurane and $2 \%$ for maintenance, balance with $\mathrm{O}_{2}$ ) laparotomy was performed. Under a dissection microscope, abdominal aorta and inferior cava vein were carefully exposed and the abdominal aorta was punctured with an 18-gauge needle until the adjacent cava vein was reached. A drop of Hystoacril (Braun) tissue glue was used to seal the aortic 
puncture. Fistula patency was visually confirmed by the presence of arterial pulsatile blood flow towards the venous circulation. Finally, abdominal cavity was closed in layers with absorbable 4-0 Vycril suture (Braun). Antibiotic (enrofloxacin $10 \mathrm{mg} \mathrm{Kg}^{-1}$ s.c.), analgesic (ketoprofen $5 \mathrm{mg} \mathrm{Kg}^{-1}$ s.c.) and saline ( $3 \mathrm{ml}$ of $0.9 \% \mathrm{NaCl}$ solution i.p.) were administrated post-surgery. Sham-operated rats underwent the exact same procedure with the only exception that no puncture was done in the aorta.

\section{Echocardiography}

Under anesthesia (1.5-2\% isoflurane balance with $\left.\mathrm{O}_{2}\right)$, transthoracic M-mode echocardiography (Mindray Z6 Vet) at week 2 and 8 post CHF surgery were performed. Recordings were made from the left parasternal shortaxis view. An increase of 1.5 -fold in the end diastolic volume (EDV) and stroke volume (SV) relative to sham condition were the criteria for CHF [16, 17, 31, 33, 34]. Left ventricle (LV) end diastolic and systolic diameter (LVEDD and LVESD, respectively) were measured from 3 consecutive cycles. LV end diastolic and systolic volume (LVEDV and LVESV, respectively) where derived from Teicholz method ([LVESV $\left.=7^{*} \mathrm{ESD}^{3} /(2.4+\mathrm{ESD})\right]$ and $\left[\mathrm{LVEDV}=7 * \mathrm{EDD}^{3} /(2.4+\mathrm{EDD})\right]$. The ejection fraction (EF) and fractional shortening (FS) were calculated from left ventricle volumes and diameters, respectively. The cardiac output $(\mathrm{CO})$ is the product from SV and heart rate (HR).

\section{Potassium diet supplementation}

Rats were randomly assigned to Sham, CHF and $\mathrm{CHF}+\mathrm{K}^{+}$groups. Sham and $\mathrm{CHF}$ received standard chow diet (Prolab ${ }^{\circledR}$ RMH3000 5P00/0.9\% $\mathrm{K}^{+}$) while $\mathrm{CHF}+\mathrm{K}^{+}$received the same formula but supplemented with $3 \% \mathrm{~K}^{+}$(Prolab $^{\circledR}$ RMH3000 5P00/2\% $\mathrm{K}^{+}$and $1 \% \mathrm{KCl}$ in the drinking water) for 6 weeks as previously described $[22,23]$. Combination of $\mathrm{K}^{+}$supplementation in both chow and tap water has been shown to increase tolerability to high-salt diets [35]. Body weight gain, daily food and water intake were registered in all groups and averaged. See Additional file 1: Table S1 for complete diets composition.

\section{Telemetry implant for blood pressure and heart rate measurements}

Radio-telemetry pressure transducer (HD-S10, ADInstruments) were implanted 7 weeks after CHF or sham surgery. Rats under isoflurane anesthesia underwent a skin incision to expose and isolate femoral artery. The tip of a pressure transducer was guided into the femoral artery and the HD-S10 digital transmitter was placed subcutaneously. Then, rats received antibiotic (enrofloxacin $10 \mathrm{mg} \mathrm{Kg}^{-1}$ s.c.) and analgesic (ketoprofen
$5 \mathrm{mg} \mathrm{Kg}{ }^{-1}$ s.c.). After 1 week of recovery, arterial blood pressure (BP) was measured in conscious rats [31, 34]. Mean arterial blood pressure (MABP), systolic blood pressure (SBP), diastolic blood pressure (DBP) and pressure pulse (PP) were derived from BP signal. Heart rate (HR) was derived from $\mathrm{dP} / \mathrm{dt}$ signal of BP.

\section{Spontaneous baroreflex}

Telemetry recording was used to analyze change in spontaneous baroreflex 8 weeks after CHF induction. MABP and HR were derived from BP signal. Baroreflex sequences where changes in $H R(\triangle H R)$ where associated with changes in MABP ( $\triangle \mathrm{MABP}$ ) were used to estimate spontaneous baroreflex function. The up sequences were analyzed apart from down sequences. Then values were plotted, and linear regression was calculated for each animal [36].

\section{Sympatho-vagal balance}

Cardiac sympathetic-vagal balance was evaluated by effects of propranolol ( $1 \mathrm{mg} \mathrm{Kg}^{-1}$ i.p.), a non-selective $\beta$-adrenergic receptor antagonist, and atropine injection ( $1 \mathrm{mg} \mathrm{Kg}^{-1}$ i.p.), a muscarinic receptor antagonist on $\mathrm{HR}$ in conscious rats. Changes in HR in response to propranolol were used as an indicator of sympathetic tone and HR responses to atropine were used as an indicator of parasympathetic tone. $\triangle \mathrm{HR}$ represent the change in $\mathrm{HR}$ respect from baseline HR [16, 33].

\section{Arrhythmia incidence}

Irregular heartbeats were visually inspected and counted as previously described [33]. Arrhythmias were defined as premature or delayed beats with changes greater than 3 standard deviations (SD) from the mean beat-to-beat interval duration. The arrhythmia index was expressed as events/hour.

\section{Resting breathing patterns and chemoreflex function}

Unrestrained whole-body plethysmography (Emka Technologies) was used to record resting breathing (RB) and chemoreflex function. RB was recorded during $2 \mathrm{~h}$ at room air. Central and peripheral chemoreflex function was evaluated during $10 \mathrm{~min}$ of hypercapnia $\left(7 \% \mathrm{~F}_{\mathrm{i}} \mathrm{CO}_{2} /\right.$ balance with $\left.\mathrm{N}_{2}\right)$ and hypoxia $\left(10 \% \mathrm{~F}_{\mathrm{i}} \mathrm{O}_{2} /\right.$ balance with $\mathrm{N}_{2}$ ) gas challenges, respectively. An interval of $20 \mathrm{~min}$ in normoxia separated the two stimuli. Tidal volume $\left(\mathrm{V}_{\mathrm{T}}\right.$ $\left.\left[\mathrm{ml} 100 \mathrm{~g}^{-1}\right]\right)$, respiratory frequency $\left(\mathrm{R}_{\mathrm{f}}\left[\right.\right.$ breath $\left.\left.\mathrm{min}^{-1}\right]\right)$ and minute volume $\left(\mathrm{V}_{\mathrm{E}}\left[\mathrm{ml} \mathrm{min}^{-1} 100 \mathrm{~g}^{-1}\right]\right)$ was obtained using ecgAUTO post-processing software (Emka Technologies). Regularity of breathing pattern was evaluated using Poincare plots of the breath-to-breath interval variability from 6 independent and random intervals of $\sim 400$ breaths. Coefficient of variation of $\mathrm{V}_{\mathrm{T}}$ was also calculated 
to evaluate oscillations in ventilatory cycles. Irregularity score (IS) was evaluated using the follow equation: $100 *\left(\mathrm{~T}_{\mathrm{TOTn}}-\mathrm{T}_{\mathrm{TOTn}-1}\right) / \mathrm{T}_{\mathrm{TOTn}-1}$ for the $\mathrm{nth}$ respiratory cycle as described previously [34].

The hypercapnic ventilatory response (HCVR) was obtained by determining the slope on the $\mathrm{V}_{\mathrm{E}}$ response between $\mathrm{F}_{\mathrm{i}} \mathrm{CO}_{2} 0.03 \%$ and $\mathrm{F}_{\mathrm{i}} \mathrm{CO}_{2} 7 \%$. The hypoxic ventilatory response (HVR) was obtained by calculating the slope between $\mathrm{V}_{\mathrm{E}}$ and $\mathrm{F}_{\mathrm{i}} \mathrm{O}_{2} 21 \%$ and $\mathrm{F}_{\mathrm{i}} \mathrm{O}_{2} 10 \%$. All experiments were conducted at ambient temperature in daily time.

Breathing disorders including apneas (cessation in ventilation for at least 3 consecutive respiratory cycles) and hypopneas (reduction in $\mathrm{V}_{\mathrm{T}}$ under $50 \%$ of normal breathing amplitude for at least 3 consecutive respiratory cycles) were scored from $1 \mathrm{~h}$ of RB recordings [34].

\section{Cardiorespiratory coupling}

Several studies showed that coupling between respiratory and cardiovascular function promotes sympathoexcitation and perpetuates the generation of breathing disorders. Accordingly, we analyzed the effects of rising dietary $\mathrm{K}^{+}$levels on cardiorespiratory coupling in the setting of non-ischemic CHF. Accordingly, coherence between $V_{T}$ and SBP were evaluated through MATLAB routine (MathWorks) as described previously [31, 34, 37, 38]. Welch's over-lapped segment averaging method were used to calculate auto- and cross-spectral estimates from 5 min recordings. Every variable underwent Fast Fourier transform (FFT). Respiratory signal oscillations were taken as the input and BP as the output for coherence analysis. Cut-off to evaluate the magnitude of mean square coherence was $0.015 \mathrm{~Hz}$ centered at the frequency of maximum spectral peak of $\mathrm{V}_{\mathrm{T}}$ in the very low frequency domain (vLF: $0.01-0.25 \mathrm{~Hz}$ ). Positive interaction between ventilation and BP were obtained from square coherence values over 0.5 (range of square coherence is $0-1)$.

\section{Cardiac function assessment}

LV function was evaluated using a pressure-volume (PV) conductance catheter (SPR-869, Millar) [33, 39]. Under anesthesia ( $\alpha$-chloralose and urethane, $800 \mathrm{mg} \mathrm{Kg}^{-1}$ and $40 \mathrm{mg} \mathrm{Kg}{ }^{-1}$, respectively) a conductance catheter was introduced into right carotid artery and advance toward LV chamber. A laparotomy was performed to visualized arteriovenous fistula and then perform a cava vein occlusion. PV-loops were recorded for $1 \mathrm{~h}$ and fifteen to twenty PV loops were used to calculate hemodynamic parameters: cardiac output (CO), ejection fraction (EF), end diastolic pressure (EDP), end systolic pressure (ESP), Parameters dependent of load were: $\mathrm{dP} / \mathrm{dt}_{\max }, \mathrm{dP} / \mathrm{dt}_{\min }$. Load-independent parameters: end-systolic pressure volume relationship (ESPVR) and end-diastolic pressure volume relationship (EDPVR) were also calculated. Data was processed using the PV-loop module of LabChart v7.3.8 software (ADInstruments).

\section{$\left[\mathrm{Na}^{+}\right]$and $\left[\mathrm{K}^{+}\right]$systemic concentrations}

Under anesthesia $\alpha$-chloralose/urethane anesthesia, arterial blood samples were obtained from the abdominal aorta using a $3 \mathrm{ml}$ syringe. A drop of arterial blood was immediately analyzed (iSTAT1 CG8+, Abbott) at the end of cardiac function assessment. Ionic concentration $\left(\mathrm{K}^{+}\right.$and $\left.\mathrm{Na}^{+}\right)$of arterial blood was analyzed.

\section{Statistical analysis}

Data is expressed as mean \pm standard error mean (SEM). Data is shown as min to max box and whiskers plot in figures. One-way or two-way ANOVA, depending on data structure, was employed to evaluate differences between groups following by Holm-Sidak post hoc test. $\mathrm{P}<0.05$ was consider as statistically significant.

\section{Results}

$\mathrm{K}^{+}$supplementation decreases arrhythmias and restores normal autonomic and baroreflex function in $\mathrm{CHF}$

$\mathrm{CHF}$ rats showed an increase in the number of cardiac arrhythmias compared to Sham rats $(67.8 \pm 15.1$ vs. $10.4 \pm 2.1$ events/hour, CHF vs. Sham, respectively; $\mathrm{p}<0.05)$. CHF rats that received diet supplemented with $\mathrm{K}^{+}$showed a significant reduction in the number of arrhythmias compared to CHF rats (31.0 \pm 3.7 vs. $67.8 \pm 15.1$ events/hour, $\mathrm{CHF}+\mathrm{K}^{+}$vs. $\mathrm{CHF}$, respectively; $\mathrm{p}<0.05$ ) (Fig. 1A, B). In agreement with previous investigations, $\mathrm{CHF}$ rats displayed a heightened cardiac sympathetic drive compared to Sham healthy rats $(\triangle H R$ to propranolol: $-97.4 \pm 9.4$ vs. $-24.5 \pm 3.6 \mathrm{bpm}$, CHF vs. Sham, respectively; $\mathrm{p}<0.05)$ and this was normalized by the enriched- $\mathrm{K}^{+}$diet in CHF. Indeed, $\mathrm{CHF}+\mathrm{K}^{+}$ rats showed a significant reduction in cardiac sympathetic tone compared to $\mathrm{CHF}$ rats $(\triangle \mathrm{HR}$ to propranolol: $-60.8 \pm 8.3 \mathrm{bpm}$ vs. $-97.4 \pm 9.4 \mathrm{bpm}, \mathrm{CHF}+\mathrm{K}^{+}$vs. CHF, respectively; $\mathrm{p}<0.05$ ) (Fig. $1 \mathrm{C}$ ). In addition, $\mathrm{CHF}$ group displayed a decreased parasympathetic drive compared to Sham ( $\Delta$ HR to atropine: $44.1 \pm 8.3$ vs. $91.2 \pm 9.2 \mathrm{bpm}$, CHF vs. Sham, respectively; $\mathrm{p}<0.05$ ) and this was not changed by $\mathrm{K}^{+}$supplementation in CHF $(44.1 \pm 8.3 \mathrm{bpm}$ and $44.8 \pm 4.1 \mathrm{bpm}, \mathrm{CHF}+\mathrm{K}^{+}$vs. $\mathrm{CHF}$, respectively) (Fig. 1D). In addition, tachycardic baroreflex gain was reduced in rats with CHF compared to Sham rats (slope: $-0.7 \pm 0.3$ vs $-2.0 \pm 0.3 \mathrm{bpm} / \mathrm{mmHg}$, CHF vs. Sham, respectively; $\mathrm{p}<0.05)$ and dietary $\mathrm{K}^{+}$supplementation in CHF significantly improved baroreflex gain (Fig. 1E). 


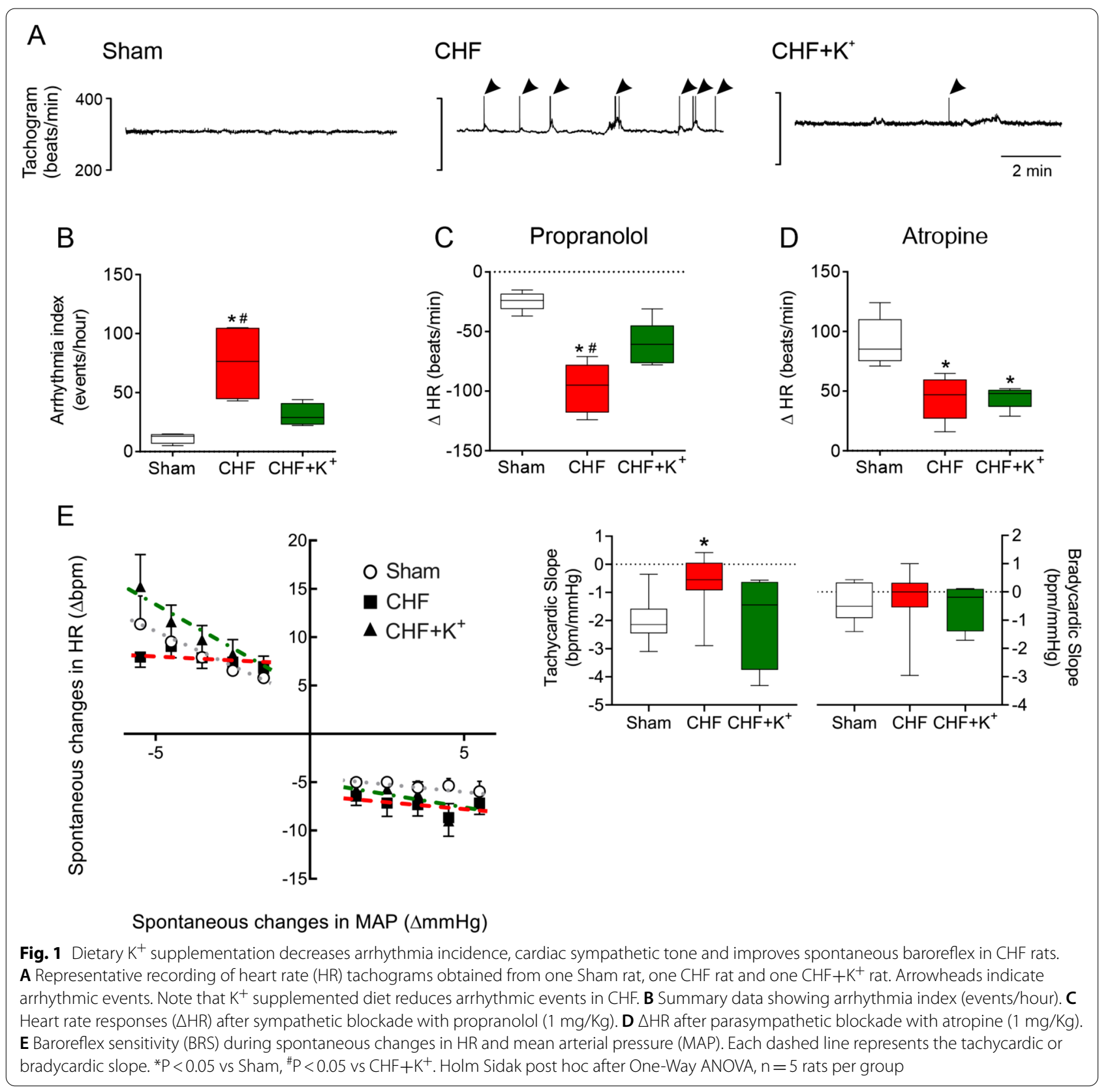

Bradycardic baroreflex responses were undistinguishable between groups (Fig. 1E).

\section{Effects of $\mathrm{K}^{+}$supplementation on breathing patterns in $\mathrm{CHF}$}

Irregular resting breathing both in frequency and amplitude of respiration were observed in CHF rats compared to Sham (Fig. 2A). Indeed, interbreath interval variability was higher in CHF rats compared to Sham (SD1: $76.6 \pm 3.3$ vs. $49.1 \pm 4.4 \mathrm{~ms}$; SD2: $124.4 \pm 11.6$ vs. $70.6 \pm 5.6 \mathrm{~ms}, \mathrm{CHF}$ vs. Sham, respectively; $\mathrm{p}<0.05$ )
(Fig. 2B-D). Furthermore, the coefficient of variation $(\mathrm{CV})$ of each tidal volume $\left(\mathrm{V}_{\mathrm{T}}\right)$ amplitude was significantly greater in CHF $(25.2 \pm 1.6$ vs $16.4 \pm 1.8 \%$, CHF vs. Sham, respectively; $\mathrm{p}<0.05$ ) (Fig. 2E). Accordingly, CHF rats showed increased overall breathing irregularity score (IS) compared to Sham rats $(13.9 \pm 0.8$ vs. $8.5 \pm 0.6 \%$, CHF vs. Sham, respectively; $\mathrm{p}<0.05)$ (Fig. 2F). Daily dietary $\mathrm{K}^{+}$supplementation in CHF rats improved breathing pattern regularity at rest compared to $\mathrm{CHF}$ untreated rats (Fig. 2A). Compared to CHF, rats that received $\mathrm{K}^{+}$diet showed significant $\left(\mathrm{CHF}+\mathrm{K}^{+} \mathrm{vs}\right.$. 
A
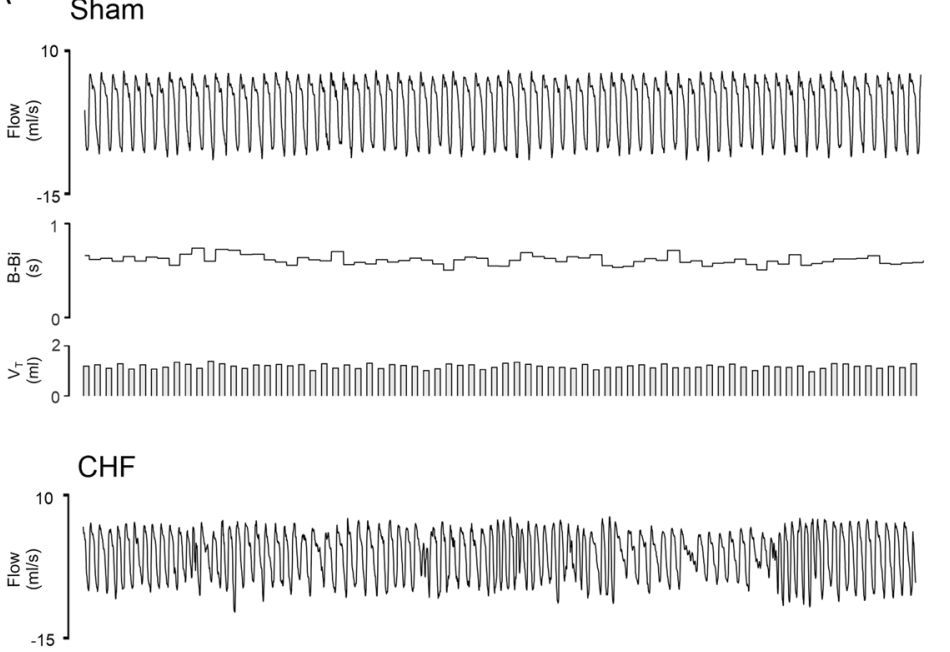

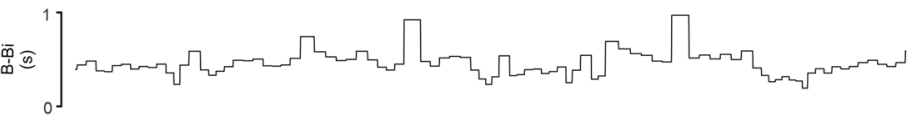

>
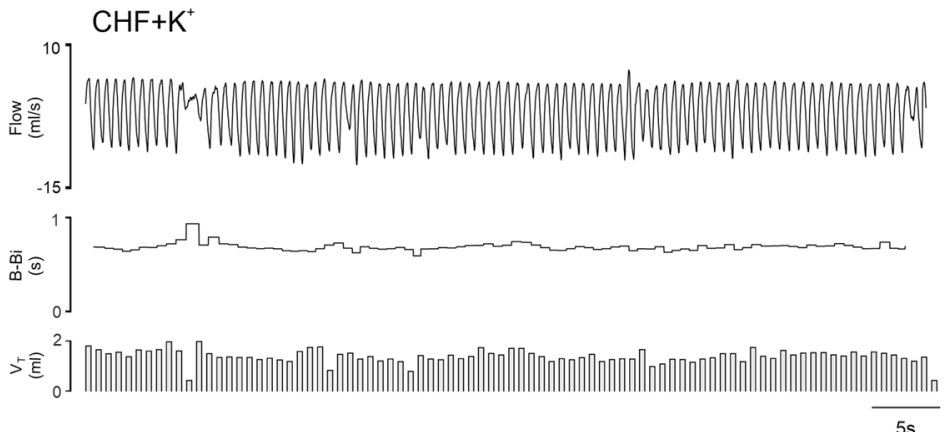

B
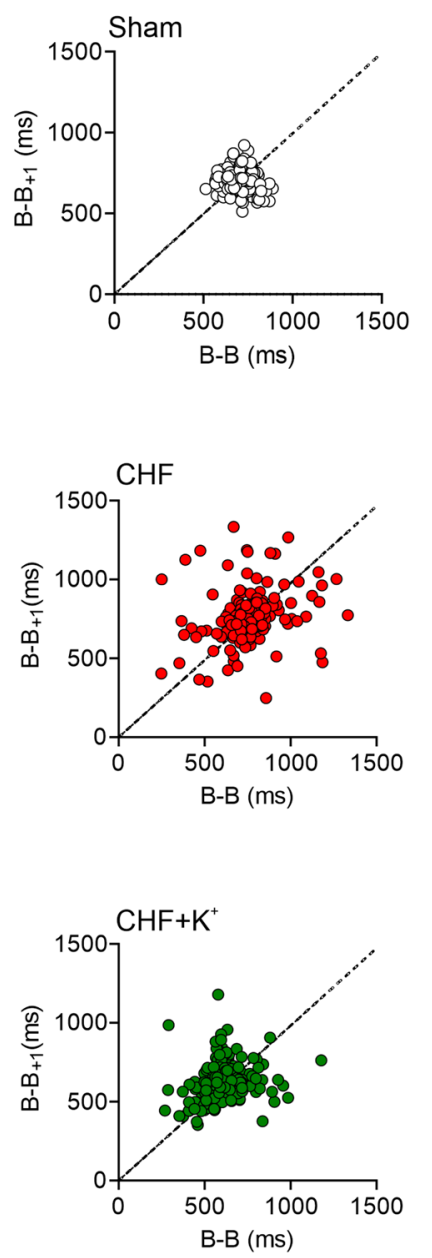

$\mathrm{F}$

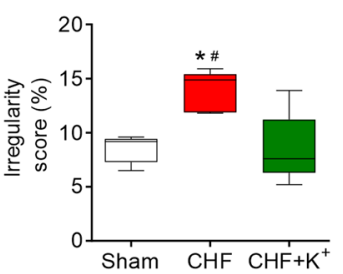

Fig. 2 Daily dietary $\mathrm{K}^{+}$supplementation improves breathing in CHF rats. A Representative ventilation recordings of ventilatory flow $(\mathrm{ml} / \mathrm{s})$, breath-to-breath interval $\left(B-B_{i}, s\right)$ and tidal volume $\left(V_{T}, m l\right)$ obtained from one Sham rat, one $C H F$ rat and one $C H F+K^{+}$rat. B Representative Poincare plots showing $B-B_{i}$ variability. C-D Summary data displaying SD1 and SD2 in all groups. Note that irregularity of B- $B_{i}$ in $C H F$ is markedly improve by dietary $\mathrm{K}^{+}$supplementation. $\mathbf{E}$ Summary data showing changes in breathing irregularity score (\%). $\mathbf{F}$ Coefficient of variation of $\mathrm{V}_{\mathrm{T}}$ amplitudes $(\%)$. $\mathrm{K}^{+}$ supplemented diet significantly reduces $V_{T}$ oscillations in $C H F .{ }^{*} P<0.05$ vs Sham, ${ }^{\#} P<0.05$ vs CHF $+K^{+}$. Holm Sidak post hoc after One-Way ANOVA, $\mathrm{n}=5$ rats per group

CHF, $\mathrm{p}<0.05)$ improvements in breath-to-breath interval variability (SD1: $57.5 \pm 3.3$ vs. $76.7 \pm 3.2 \mathrm{~ms}$ ) and $\mathrm{V}_{\mathrm{T}}$ oscillations (CV of $\mathrm{V}_{\mathrm{T}}: 16.7 \pm 2.3$ vs. $\left.25.5 \pm 1.6 \%\right)$ and $\mathrm{IS}$
$(8.5 \pm 1.5$ vs. $13.9 \pm 0.8 \%)$ (Fig. $2 \mathrm{~B}-\mathrm{F})$. Apneas and hypopneas were also increased in CHF compared to Sham (apneas: $4.8 \pm 0.6$ vs. $1.4 \pm 0.4$; hypopneas: $3.6 \pm 0.5$ vs. $2.4 \pm 0.5$ events/hour, respectively; $\mathrm{p}<0.05$ ). While $\mathrm{K}^{+}$ 


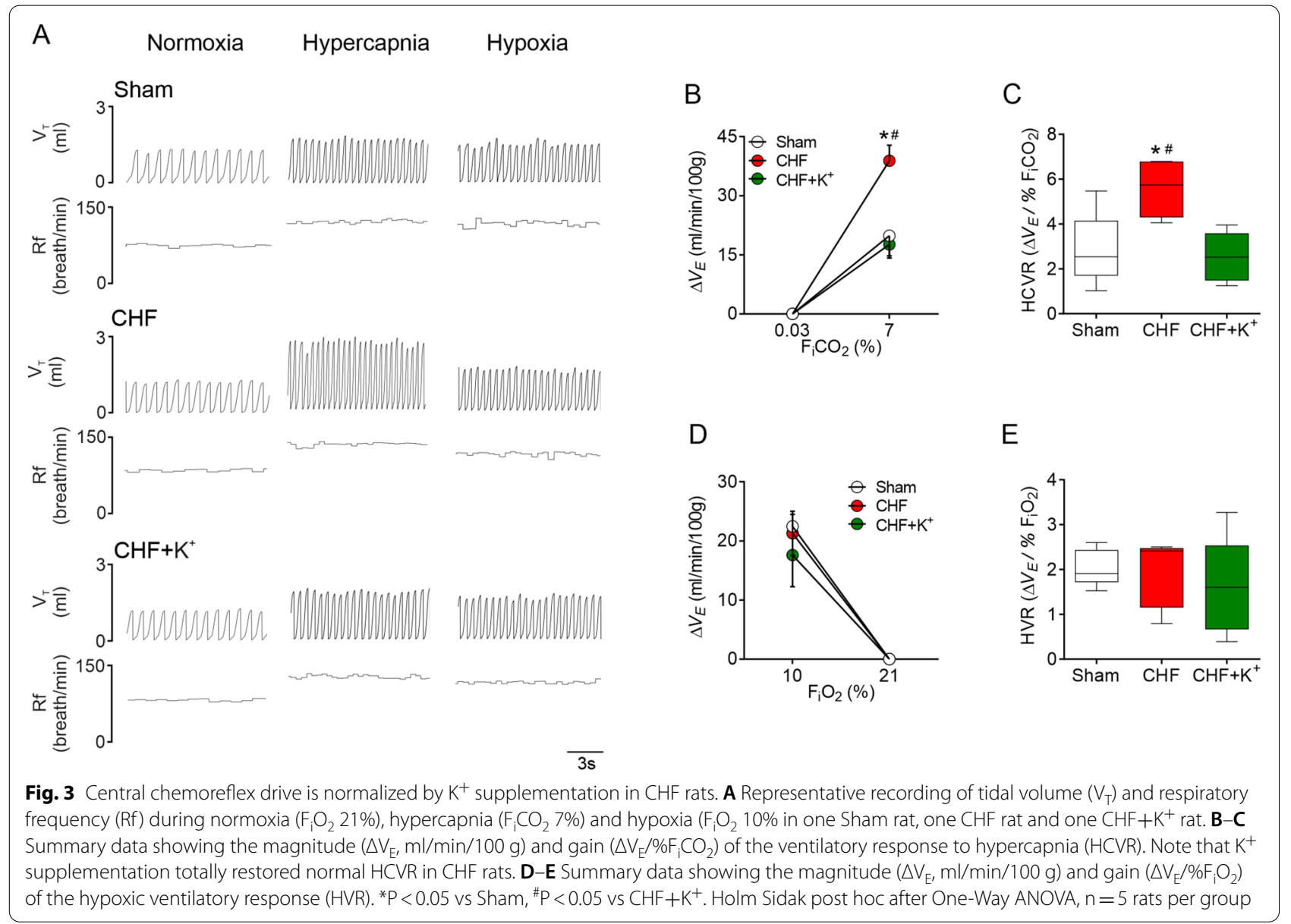

supplementation in CHF decreases the incidence of apneas this was not rise statistical significance (Additional file 1: Table S2). Frequency of sighs and post sigh apneas, as well as apnea duration, were not different between groups (Additional file 1: Table S2).

\section{$\boldsymbol{K}^{+}$supplemented diet decreases central chemoreflex drive in $\mathrm{CHF}$}

CHF rats showed an exaggerated central chemoreflex drive compared to Sham rats as evidenced by an enhanced ventilatory reflex response to hypercapnia (HCVR) $\left(5.6 \pm 0.6\right.$ vs. $2.8 \pm 0.7 \Delta \mathrm{V}_{\mathrm{E}} / \mathrm{F}_{\mathrm{i}} \mathrm{CO}_{2} \quad 7 \%$, CHF vs. Sham, respectively; $\mathrm{p}<0.05$ ) (Fig. $3 \mathrm{~A}-\mathrm{C}$ ). The observed potentiation in HCVR in CHF was abolished by dietary $\mathrm{K}^{+}$supplementation $(2.5 \pm 0.5$ vs. $5.6 \pm 0.6$ $\Delta \mathrm{V}_{\mathrm{E}} / \% \mathrm{~F}_{\mathrm{i}} \mathrm{CO}_{2}, \mathrm{CHF}+\mathrm{K}^{+}$vs. $\mathrm{CHF}$, respectively; $\left.\mathrm{p}<0.05\right)$ (Fig. 3C). No differences in the hypoxic ventilatory response (HVR) were found between groups $(2.0 \pm 0.2$ vs. $1.9 \pm 0.3$ vs. $1.6 \pm 0.5 \Delta \mathrm{V}_{\mathrm{E}} / \% \mathrm{~F}_{\mathrm{i}} \mathrm{O}_{2}$, Sham vs. CHF vs. $\mathrm{CHF}+\mathrm{K}^{+}$, respectively) (Fig. 3D, E). Also, no significant changes in resting $\mathrm{V}_{\mathrm{T}}$ nor in respiratory frequency in normoxia were found between experimental conditions (Additional file 1: Table S3).

\section{Effects of $\mathrm{K}^{+}$supplementation in the diet on pathological cardiorespiratory coupling in $\mathrm{CHF}$}

Rats with $\mathrm{CHF}$ exhibit cardiorespiratory coupling evidenced by the presence of significant coherence between $\mathrm{V}_{\mathrm{T}}$ and SBP oscillations (Coherence: $0.8 \pm 0.1$ vs. $0.07 \pm 0.1, \mathrm{CHF}$ vs. Sham, respectively; $\mathrm{p}<0.05)$. In addition, coherence in CHF was characterized by a positive phase angle $\left(53.2 \pm 18.6^{\circ}\right)$ supporting that breathing oscillations and blood pressure were in phase with the cyclic changes in $\mathrm{V}_{\mathrm{T}}$ amplitudes. CHF rats that received $\mathrm{K}^{+}$supplemented diet displayed a decrease in the magnitude of coherence between $\mathrm{V}_{\mathrm{T}}$ and SBP to levels comparable to the ones obtained in Sham rats (Coherence: $0.5 \pm 0.1$ vs. $0.8 \pm 0.1$, respectively; $\mathrm{p}<0.05$ ) (Fig. $4 \mathrm{~A}$, B). No differences in baseline SBP were found between groups (Additional file 1: Table S4). High coherence values between ventilation and heart rate were found in all groups (Fig. 4C). In summary, dietary $\mathrm{K}^{+}$supplementation ameliorates the potentiated respiratory-sympathetic 


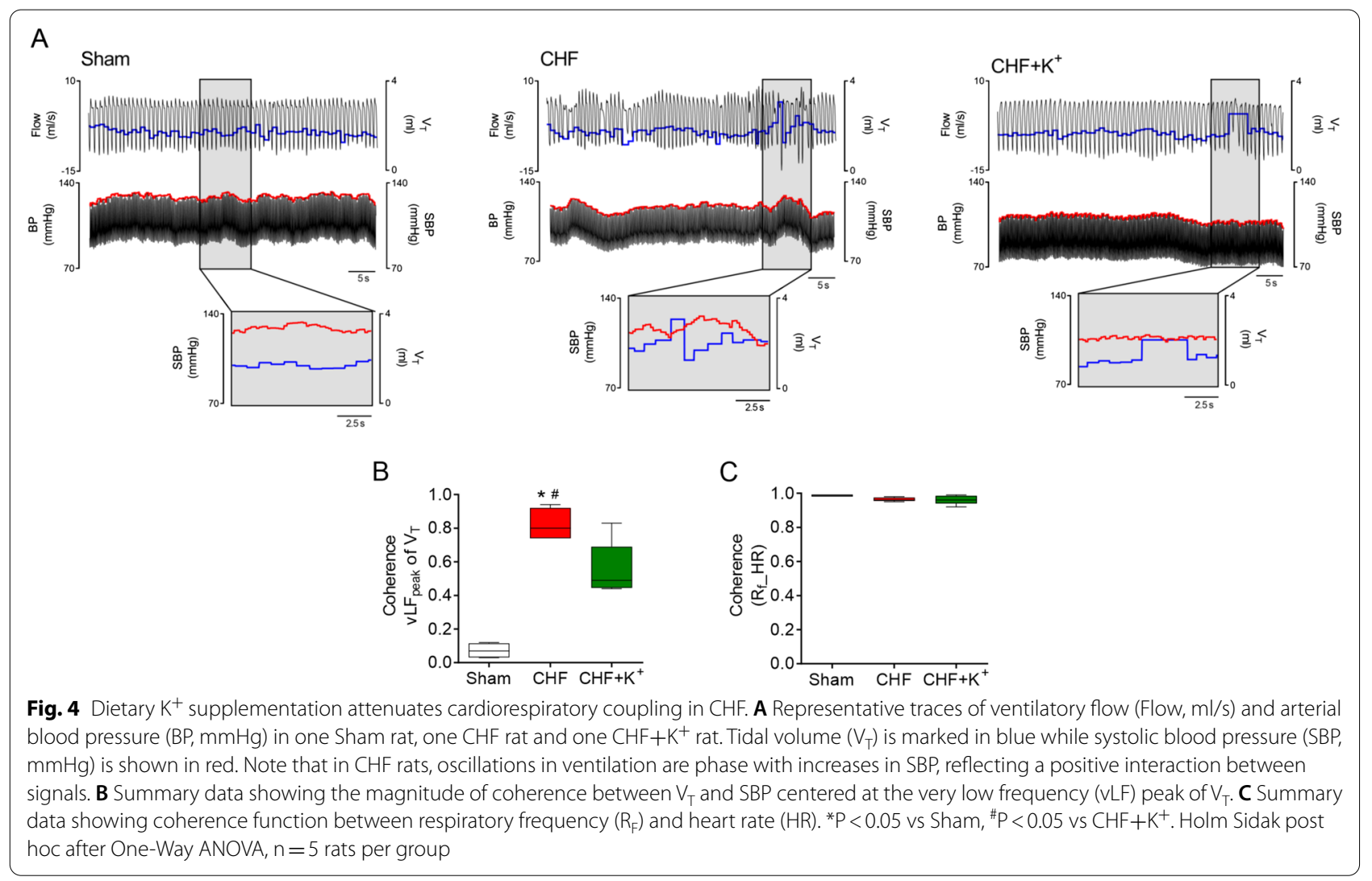

coupling in non-ischemic CHF rats, one pathophysiological hallmark of CHF disease.

\section{Effect of dietary $\mathrm{K}^{+}$supplementation on echocardiographic parameters}

Both $\mathrm{CHF}$ and $\mathrm{CHF}+\mathrm{K}^{+}$had a significant increase in LVEDV and LVESV compared to Sham rats (Fig. 5). Furthermore, $\mathrm{CHF}$ rats under $\mathrm{K}^{+}$supplemented diet showed similar stroke volume, LV chamber diameter and ejection fraction compared to untreated CHF rats (Fig. 5A-G; Additional file 1: Table S5). Accordingly, cardiac hypertrophy index was not different in CHF animals compared to $\mathrm{CHF}+\mathrm{K}^{+}$animals (Additional file 1: Table S5). No difference in body weight (BW) at the end of the experimental protocol were found between experimental conditions (Additional file 1: Table S5). Indeed, daily food intake was similar between groups (Fig. $5 \mathrm{H}$ ). Plasma levels of $\left[\mathrm{Na}^{+}\right]$ and $\left[\mathrm{K}^{+}\right]$were comparable between CHF animals and Sham animals (Fig. 5J, K). On the contrary, dietary $\mathrm{K}^{+}$ supplementation in CHF significantly increased plasma $\left[\mathrm{K}^{+}\right]$concentrations and reduced $\left[\mathrm{Na}^{+}\right]$concentration when compared to CHF untreated animals (Fig. 5J, K). Accordingly, $\left[\mathrm{Na}^{+} / \mathrm{K}^{+}\right]$plasma ratio was significantly lower in $\mathrm{CHF}+\mathrm{K}^{+}\left(28.8 \pm 1.2\right.$ vs. $35.2 \pm 1.6, \mathrm{CHF}+\mathrm{K}^{+}$vs. CHF, respectively; $\mathrm{p}<0.05)$.

\section{Effects of dietary $\mathrm{K}^{+}$supplementation on cardiac function in $\mathrm{CHF}$}

Cardiac diastolic dysfunction has been described in experimental non-ischemic CHF [16, 33]. Indeed, we found a significant increase in LV-end diastolic pressure (LVEDP) in CHF rats compared to Sham rats and this was not significantly reduced by enriched- $\mathrm{K}^{+}$diet in CHF (Additional file 1: Table S6). Since cardiac diastolic function is influenced by ventilation, we determined ventilation-dependent modulation of cardiac function during each inspiratory and expiratory cycles [40]. Intraventricular pressures at the end of diastole (nEDV) during inspiration (ins) were similar between Sham and CHF groups (Fig. 6A, B). However, CHF animals showed a $\sim$ twofold increase in intraventricular pressures during expiration (exp) $(332.9 \pm 95.0$ vs. $162.8 \pm 108.2 \%$ exp, CHF vs. Sham, respectively; $\mathrm{p}<0.05)$. In $\mathrm{CHF}+\mathrm{K}^{+}$animals, the exacerbated increase in nEDV during expiration was abolished and the values were comparable to ones obtained in Sham rats $\left(159.9 \pm 28.7\right.$ vs. $162.8 \pm 108.2 \%$ exp, $\mathrm{CHF}+\mathrm{K}^{+}$ vs. Sham, respectively; $\mathrm{p}<0.05)$. Accordingly, $\Delta$ Pressures between exp-ins were larger in CHF rats compared to Sham rats $(232.9 \pm 59.6$ vs. $67.8 \pm 34.9 \%$, CHF vs. Sham, respectively; $\mathrm{p}<0.05)$ and this effect was absent in $\mathrm{CHF}+\mathrm{K}^{+}$rats (Fig. 6C, D). 


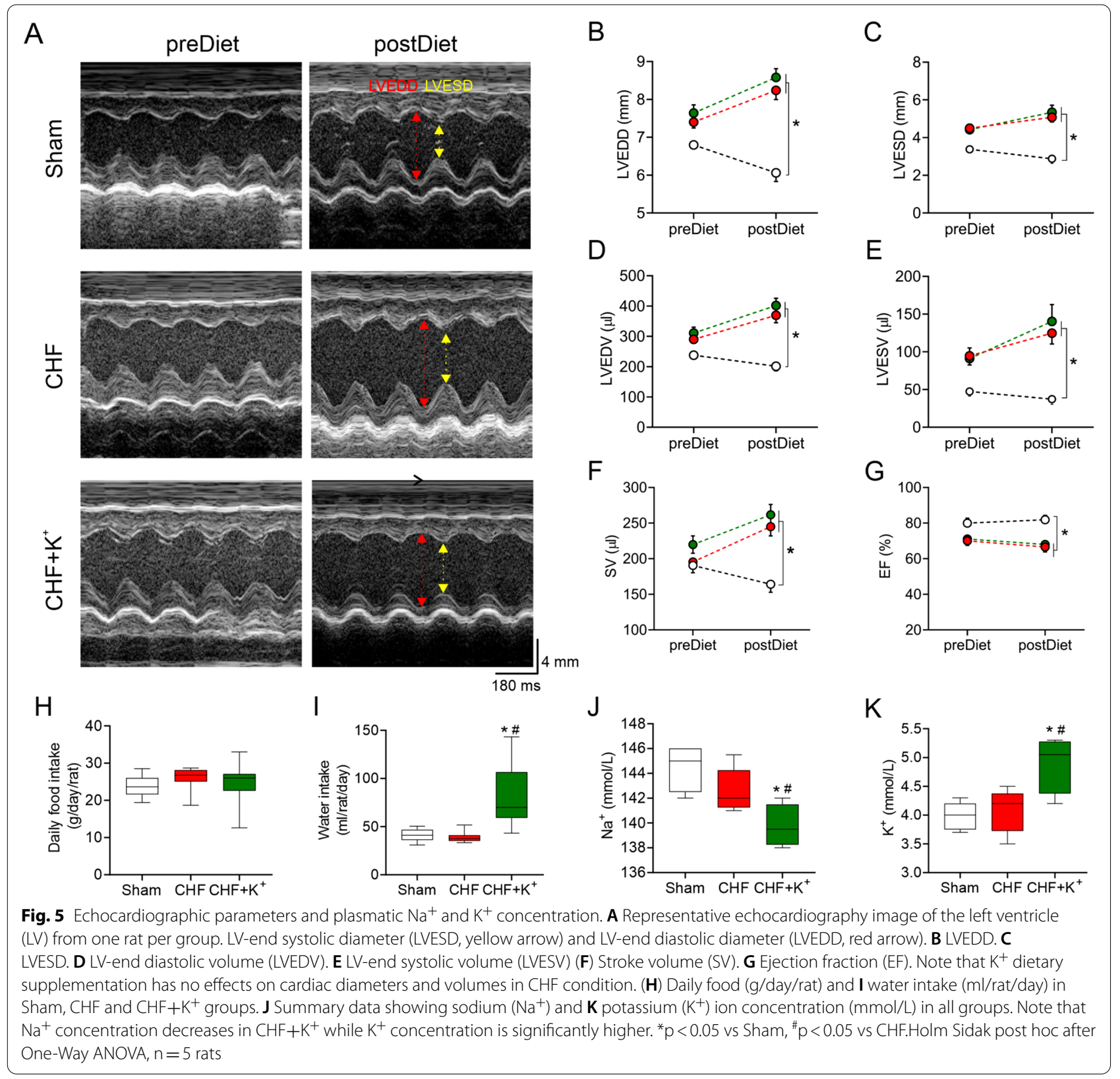

\section{Discussion}

This proof-of-concept study describes, for the first time, the beneficial effects of daily dietary $\mathrm{K}^{+}$supplementation on major pathophysiological (i.e. autonomic imbalance, breathing disorders) mechanisms associated with the development/maintenance/progression of nonischemic CHF. We found that dietary $\mathrm{K}^{+}$supplementation improved: (i) cardiac autonomic control balance; (ii) arrhythmia incidence; (iii) breathing pattern regularity; (iv) central respiratory chemoreflex; and (v) cardiorespiratory coupling. Together, our results support that $\mathrm{K}^{+}$ supplementation of the diet improves cardiorespiratory outcomes in CHF.

Increasing dietary $\mathrm{K}^{+}$levels has been linked to several cardiovascular benefits. Indeed, evidence from animal studies, clinical trials and meta-analyses have shown that enriched potassium diets are closely linked to marked reductions in the incidence of stroke, protects against vascular injury and reduces cardiac oxidative damage $[24,26,41-45]$. Here, we showed that supplementation of an enriched $\mathrm{K}^{+}$diet in experimental non-ischemic $\mathrm{CHF}$ markedly reduces sympathoexcitation, normalizes chemoreflex function and improves cardiac function. 
A

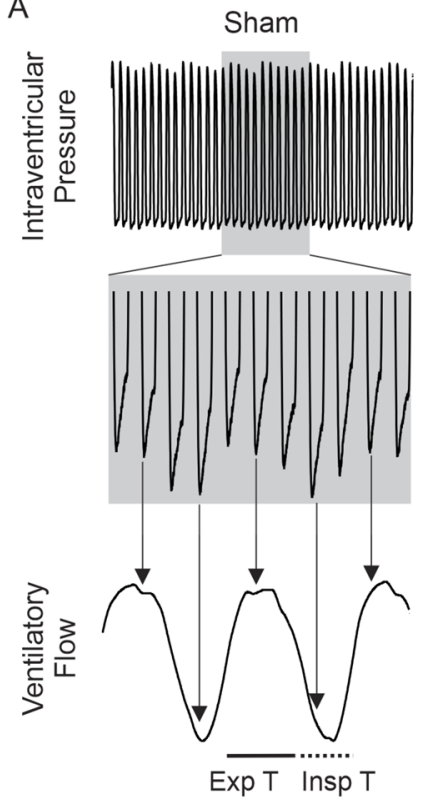

B

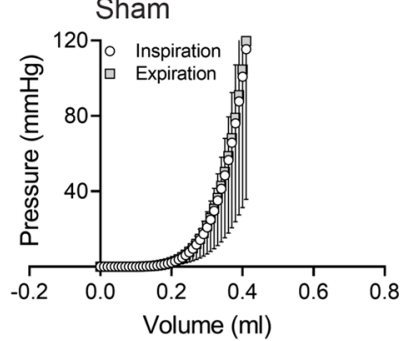

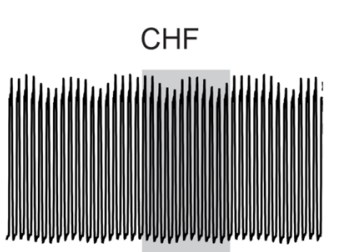
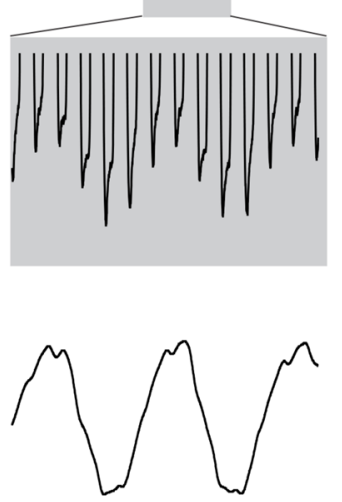

$\mathrm{CHF}$

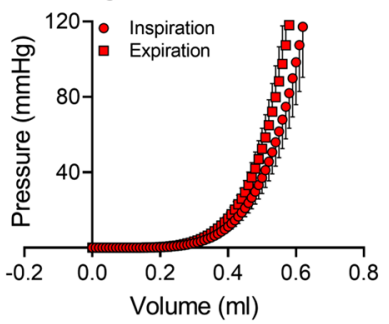

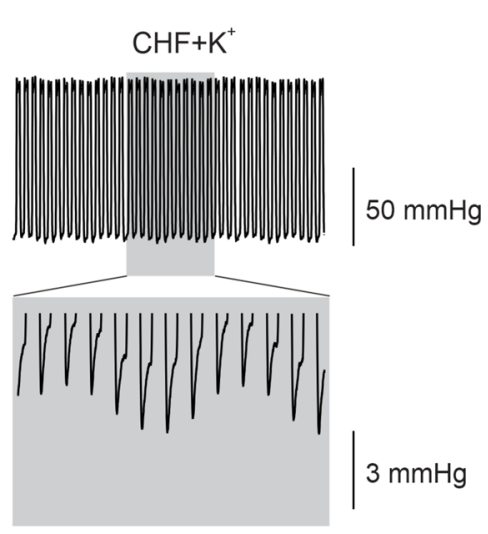

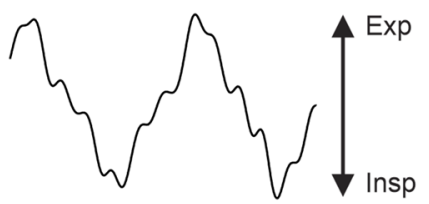

$\frac{\mid}{0.5 \mathrm{~s}} 6 \mathrm{ml} / \mathrm{s}$

$\mathrm{CHF}+\mathrm{K}^{+}$

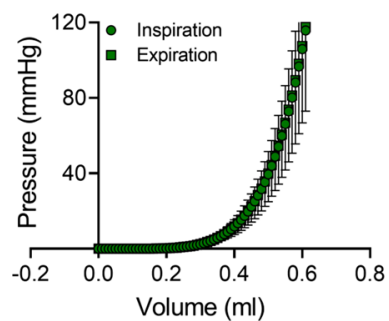

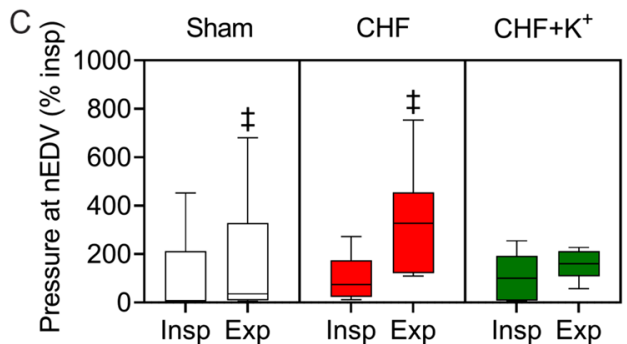

D

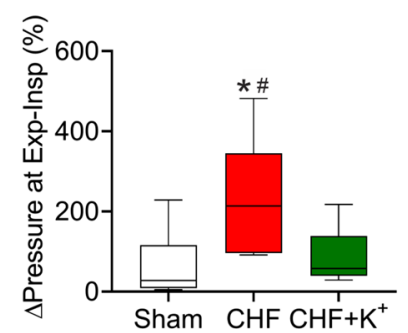

Fig. 6 Dietary $\mathrm{K}^{+}$supplementation improves cardiac diastolic function in CHF rats. A Representative recording of left ventricle (LV) intraventricular pressure from one Sham rat, one $\mathrm{CHF}$ rat and one $\mathrm{CHF}+\mathrm{K}^{+}$rat (Upper panel). Lower panel shows ventilatory flows in each section. Note that end diastolic pressure (EDP) is modulated by the ventilatory cycle. B End diastolic pressure volume relationship assessed by single-beat PV-loop analysis during the expiratory and inspiratory phases of the breathing cycle. C Summary data of normalized EDP ( $\mathrm{nEDP}$ ) during inspiration and expiration. Note that the EDP was severely modulated by the ventilatory cycle in CHF rats and this was abolished by $\mathrm{K}^{+}$diet supplementation. D Summary data showing percent changes in $\triangle$ intraventricular pressures at Exp-Insp. Two-way ANOVA (C) and One-way ANOVA (D), followed by Holm Sidak posthoc. ${ }^{\ddagger} \mathrm{P}<0.05$ vs. Insp; ${ }^{*} \mathrm{P}<0.05$ vs. Sham, $\# \mathrm{P}<0.05$ vs $\mathrm{CHF}+\mathrm{K}^{+} \mathrm{n}=5$ rats per group

The precise mechanism underlying the salutary benefits of enriched- $\mathrm{K}^{+}$diets in cardiac failure are not known. However, decreases in cardiac pre-load has been associated to daily ingestion of high $\mathrm{K}^{+}$diets. Indeed, dietary
$\mathrm{K}^{+}$supplementation decreases the expression of the $\mathrm{Na}^{+}-\mathrm{Cl}^{-}$contransporter (NCC) in the distal nephron which reduce $\mathrm{Na}^{+}$circulating levels (less reabsortion), and leads to effective reductions in circulating blood 
volume [45-47]. Our results showed that enriched $\mathrm{K}^{+}$ diet in CHF significantly decreased plasma $\left[\mathrm{Na}^{+}\right]$. The later support that high $\mathrm{K}^{+}$diet reduced $\mathrm{Na}^{+}$reabsortion in $\mathrm{CHF}$ and suggests that high $\mathrm{K}^{+}$may also reduce circulating volume being the outcome an improved cardiac function due to volume unloading. Further studies will be needed to totally address whether enriched $\mathrm{K}^{+}$diets in $\mathrm{CHF}$ elicit changes in circulating blood volume.

It has been shown that during early stage of CHF, sympathoexcitation and RAS activation act as an adaptative physiological mechanism to improve cardiovascular function; however, eventually it becomes maladaptive and sustain disease progression [15, 48]. Importantly, chronic sympathetic hyperactivity and RAS promotes arrhythmia incidence and the further deterioration of cardiac function $[7,27,33]$. One major neuronal network that has been proposed to contribute, at least in part, to sustained high sympathetic activity in CHF encompassed the subfornical organ, paraventricular nucleus of the hypothalamus and the rostral ventrolateral medulla (SFO-PVN-RVLM) [15]. SFO is a highly vascularized nuclei with a permeable blood brain barrier (BBB) and is considered a major source of brain AngII $[15,49,50]$. Furthermore, it has been shown that AngII elicits increase in sympathetic outflow by acting on the $\mathrm{SFO} / \mathrm{PVN}[6,15,51]$ or directly on the RVLM once BBB is disrupted [52]. The specific mechanisms underlying AngII-induced sympathoexcitation in the setting of CHF have not been fully dilucidated. However, one accepted mechanism is associated with AngII-induced oxidative stress and neuronal hyperexcitability [15, 53]. Indeed, activation of $\mathrm{AT}_{1} \mathrm{R}$ which is present in the SFO, PVN and RVLM promotes ROS formation via NADPH oxidase $[15,50,53-55]$. Accordingly, experimental non-ischemic CHF rats showed increased levels of phosphorylated NADPH oxidase in the RVLM and this was closely linked to ROS levels and autonomic imbalance [17]. In the present study we found that dietary $\mathrm{K}^{+}$supplementation in $\mathrm{CHF}$ rats reduced the heightened cardiac sympathetic outflow and reduced arrhythmogenesis. It is worth noting that the present study was not intended to provide a detailed description of the molecular signaling pathways by which enriched $\mathrm{K}^{+}$diets reduced sympathoexcitation in CHF but rather to highlight its potential to improve cardiovascular and ventilatory outcomes. However, previous studies showing that dietary $\mathrm{K}^{+}$downregulates renin and angiotensin-I converting enzyme and reduce AngII generation [22, 23] allow us to speculate that one potential mechanism associated with the beneficial effects of $\mathrm{K}^{+}$supplementation in CHF may be linked to RAS regulation. Future studies should focus on uncovering the molecular footprints related to $\mathrm{K}^{+}$supplementation and cardiovascular regulation in the setting of CHF.
Altered chemoreflex function play a pivotal role in the pathophysiology of CHF [16, 31, 56-58]. Indeed, an increased ventilatory response to hypercapnia associated with an enhanced chemoreceptor function is associated with heightened sympathetic nerve activity, cardiac arrhythmogenesis and breathing disturbances in humans $[56,59]$. More importantly, the former is closely linked to higher mortality risk [59]. Here, we confirmed and extend previous results showing that in CHF alterations in chemoreflex response are associated with cardiorespiratory disorders $[16,31,58]$, but also added new and novel findings showing that dietary $\mathrm{K}^{+}$supplementation represents a useful strategy to normalize chemoreflex function in CHF. How enriched $\mathrm{K}^{+}$diet reduced central chemoreflex sensitivity in non-ischemic CHF is unknown and deserves future investigations. Interestingly, data from epidemiological studies strongly suggests that healthy dietary interventions (i.e. $\mathrm{K}^{+}$supplemented diets) may improve cardiovascular outcomes in several diseases [19-21]. Here, we provided the first evidence showing that daily dietary $\mathrm{K}^{+}$supplementation significantly improves both cardiovascular and respiratory function in experimental non-ischemic CHF. Future and larger studies are needed to fully uncover the salutary potential of dietary $\mathrm{K}^{+}$supplementation in CHF pathophysiology.

Several limitations are inherent in our study. Experimental CHF shows several relevant pathophysiological hallmarks of human non-ischemic CHF such as autonomic imbalance, increased cardiac arrhythmogenesis, alterations in breathing and cardiorespiratory coupling. However, it lacks cardiometabolic disorders (i.e. diabetes mellitus, hypertension, obesity) which has been associated with non-ischemic CHF onset and progression. Nevertheless, we found that $\mathrm{K}^{+}$diet supplementation markedly improved cardiorespiratory outcomes in experimental non-ischemic CHF. Though, caution should be taken when extrapolating these results into human non-ischemic CHF due to the well-known differences between rodents and large mammal physiology. Also, we cannot rule out long-term effects of $\mathrm{K}^{+}$supplemented diets on CHF. However, Chang and cols. [60] showed that adult subjects receiving potassium-enriched diets for 31 months displayed significantly lower cardiovascular disease mortality. Also, potassium-enriched diets appear to be well tolerated up to 31 months in humans. Whether this can be directly translated into human non-ischemic CHF patients is not clear. Future studies in both experimental and human non-ischemic CHF are required to fully determine the effects of long-term administration of potassium-enriched diets on cardiorespiratory function. 


\section{Conclusion}

Together, dietary $\mathrm{K}^{+}$supplementation exerts beneficial effects on cardiorespiratory function in experimental CHF. This study provide first comprehensive physiological data that support the salutary effects of $\mathrm{K}^{+}$ supplementation on the maintenance of heightened cardiac sympathetic activity and breathing disturbances in CHF. In addition, we acknowledge that this study was not intended to provide the exact cellular mechanism of dietary $\mathrm{K}^{+}$- mediated physiological outcomes. Accordingly, upcoming research should focus on the cellular/molecular mechanisms associated with the beneficial effects of daily dietary $\mathrm{K}^{+}$supplementation in the setting of non-ischemic CHF.

\begin{abstract}
Abbreviations
Angll: Angiotensin II; AT ${ }_{1}$ : Angll receptor type I; BRS: Baroreflex sensitivity; BW: Body weight; CHF: Chronic heart failure; DBP: Diastolic blood pressure; EF: Ejection fraction; Exp: Expiratory phase; FS: Fractional shortening; HCVR: Hypercapnic ventilatory response; HR: Heart rate; HVR: Hypoxic ventilatory response; HW: Heart weight; Ins: Inspiratory phase; IS: Irregularity sore; $\mathrm{K}^{+}$: Potassium; LVEDD: Left ventricular end diastolic diameter; LVEDP: Left ventricular end diastolic pressure; LVEDV: Left ventricular end diastolic volume; LVESD: Left ventricular end systolic diameter; LVESP: Left ventricular end systolic pressure; LVESV: Left ventricular end systolic volume; MABP: Mean arterial blood pressure; NADPH: Nicotinamide adenine dinucleotide phosphate; nEDP: Normalized end diastolic pressure; PP: Pulse pressure; PV: Pressure-volume; PVN: Paraventricular nucleus; RAS: Renin-angiotensin-system; R: Respiratory frequency; ROS: Reactive oxygen species; RVLM: Rostral ventrolateral medulla; SBP: Systolic blood pressure; SFO: Subfornical organ; SV: Stroke volume; $V_{E}$ : Minute volume; $V_{\mathrm{T}}$ : Tidal volume.
\end{abstract}

\section{Supplementary Information}

The online version contains supplementary material available at https://doi. org/10.1186/s40659-021-00365-z.

Additional file 1: Table S1. Experimental diets compositions. Table S2. Effect of $\mathrm{K}^{+}$supplementation on respiratory disorders incidence in CHF condition. Table S3. Effects of $\mathrm{K}^{+}$supplemented in the diet on ventilatory parameters in CHF rats. Table S4. Arterial blood pressure and dietary $\mathrm{K}^{+}$supplementation in CHF. Table S5. Echocardiography parameters. Table S6. Effect of $\mathrm{K}^{+}$supplemented diet on intraventricular cardiac parameters.

\section{Acknowledgements}

We thank Mr. Fidel Flores for his help in managing the animal facility. We acknowledge BioRender for helping with design for Additional file 1: Fig. S1.

\section{Authors' contributions}

KGS collected, analyzed, and interpreted data, and contributed to the preparation of the manuscript. KVP, CT, DCA and HSD performed data collection and analysis, and contributed to the preparation of the manuscript. EDJ, DO, $\mathrm{ALH}$ and IV contributed to the manuscript. CPV, NCI, FO and RDR performed data interpretation and contributed to the preparation of the manuscript. RDR contributed to the concept of the project and experimental design. All data collection was undertaken in the laboratory of RDR. All authors read and approved the final manuscript.

\section{Funding}

This work was supported by Fondo de Desarrollo Científico y Tecnológico FONDECYT 1180172 and the Basal Centre of Excellence in Aging and
Regeneration (AFB 170005; ACE 210009) of Pontificia Universidad Católica de Chile, and a donation of SQM to the Pontificia Universidad Católica de Chile.

\section{Availability of data and materials}

The data presented in this study are available on request from the corresponding author. The data are not publicly available due to current funding source restrictions.

\section{Declarations}

\section{Ethics approval and consent to participate}

The study was approved by the Ethical-Scientific Committee of the Facultad de Ciencias Biológicas, Pontificia Universidad Católica de Chile (Protocol ID 170710022)

\section{Consent for publication}

Not applicable.

\section{Completing interests}

The authors declare no conflict of interest.

\section{Author details}

${ }^{1}$ Laboratory of Cardiorespiratory Control, Department of Physiology, Pontificia Universidad Católica de Chile, Santiago, Chile. ${ }^{2}$ Centro de Excelencia en Biomedicina de Magallanes (CEBIMA), Universidad de Magallanes, Punta Arenas, Chile. ${ }^{3}$ Centro de Fisiología y Medicina de Altura, Departamento Biomédico, Facultad de Ciencias de la Salud, Universidad de Antofagasta, Antofagasta, Chile. ${ }^{4}$ Mechanisms of Myelin Formation and Repair Laboratory, Instituto de Ciencias Biomédicas, Facultad de Ciencias de Salud, Universidad Autónoma de Chile, Santiago, Chile. ${ }^{5}$ Facultad de Medicina y Ciencia, Universidad San Sebastián, Santiago, Chile. ${ }^{6}$ Centro de Envejecimiento y Regeneración (CARE), Pontificia Universidad Católica de Chile, Santiago, Chile.

Received: 15 September 2021 Accepted: 9 December 2021

Published online: 24 December 2021

\section{References}

1. Ponikowski P, Anker SD, AlHabib KF, Cowie MR, Force TL, Hu S, Jaarsma T, Krum H, Rastogi V, Rohde LE, Samal UC, Shimokawa H, Siswanto BB, Sliwa K, Filippatos G. Heart failure: preventing disease and death worldwide. Eur J Heart Fail. 2014;1:4-25.

2. Desai AS, Stevenson LW. Rehospitalization for heart failure: predict or prevent? Circulation. 2012;126:501-6.

3. Yoon $\mathrm{S}$, Eom $\mathrm{GH}$. Heart failure with preserved ejection fraction: present status and future directions. Exp Mol Med. 2019;51:1-9.

4. van der Wal HH, van Deursen VM, van der Meer P, Voors AA. Comorbidities in heart failure. Handb Exp Pharmacol. 2017;243:35-66.

5. Yancy CW, Jessup M, Bozkurt B, Butler J, Casey DE Jr, Colvin MM, Drazner MH, Fonarow GS, Geraci SA, Horwich T, Januzzi JL, Johnson MR, Kasper EK, Levy WC, Masoudi FA, McBride PE, McMurray JJV, Mitchell JE, Peterson PN, Riegel B, Sam F, Stevenson LW, Wilson-Tang WH, Tsai EJ, Wilkoff BL. 2013 ACCF/AHA guideline for the management of heart failure: a report of the American College of Cardiology Foundation/American Heart Association Task Force on Practice Guidelines. J Am Coll Cardiol. 2013;62:147-239.

6. Kishi T. Heart failure as an autonomic nervous system dysfunction. J Cardiol. 2012;59:117-22.

7. Florea VG, Cohn JN. The autonomic nervous system and heart failure. Circ Res. 2014;114:1815-26.

8. Franciosi S, Perry FK, Roston TM, Armstrong KR, Claydon VE, Sanatani S. The role of the autonomic nervous system in arrhythmias and sudden cardiac death. Auton Neurosci. 2017;205:1-11.

9. Lanfranchi PA, Braghiroli A, Bosimini E, Mazzuero G, Colombo R, Donner CF, Giannuzzi P. Prognostic value of nocturnal Cheyne-Stokes respiration in chronic heart failure. Circulation. 1999;99:1435-40.

10. Bitter T, Westerheide N, Prinz C, Hossain MS, Vogt J, Langer C, Horstkotte D, Oldenburg O. Cheyne-Stokes respiration and obstructive sleep apnoea are independent risk factors for malignant ventricular arrhythmias 
requiring appropriate cardioverter-defibrillator therapies in patients with congestive heart failure. Eur Heart J. 2011;32:61-74.

11. Sciarretta S, Paneni F, Palano F, Chin D, Tocci G, Rubattu S, Volpe M. Role of the renin-angiotensin-aldosterone system and inflammatory processes in the development and progression of diastolic dysfunction. Clin Sci. 2019;116:467-77.

12. $\mathrm{XuB}, \mathrm{Li} \mathrm{H}$. Brain mechanisms of sympathetic activation in heart failure: roles of the renin-angiotensin system, nitric oxide and pro-inflammatory cytokines. Mol Med Rep. 2015:12:7823-9.

13. Griendling KK, Minieri CA, Ollerenshaw JD, Alexander RW. Angiotensin II stimulates NADH and NADPH oxidase activity in cultured vascular smooth muscle cells. Circ Res. 1994;74:1141-8.

14. Koba S, Hisatome I, Watanabe T. Central command dysfunction in rats with heart failure is mediated by brain oxidative stress and normalized by exercise training. J Physiol. 2014;592:3917-31.

15. Díaz HS, Toledo C, Andrade DC, Marcus NJ, Del Rio R. Neuroinflammation in heart failure: new insights for an old disease. J Physiol. 2019;598:33-59.

16. Toledo C, Andrade DC, Lucero C, Arce-Alvarez A, Díaz HS, Aliaga V, Schultz HD, Marcus NJ, Manriquez M, Faúndez M, Del Rio R. Cardiac diastolic and autonomic dysfunction are aggravated by central chemoreflex activation in heart failure with preserved ejection fraction rats. J Physiol. 2017:595:2479-95.

17. Andrade DC, Arce-Alvarez A, Toledo C, Díaz HS, Lucero C, Schultz HD, Marcus NJ, Del Rio R. Exercise training improves cardiac autonomic control, cardiac function, and arrhythmogenesis in rats with preserved-ejection fraction heart failure. J Appl Physiol. 2017;123:567-77.

18. Dahl LK, Leitl G, Heine M. Influence of dietary potassium and sodium/ potassium molar ratios on the development of salt hypertension. J Exp Med. 1972;136:318-30.

19. Rodrigues SL, Baldo MP, Machado RC, Forechi L, Molina MDCB, Mill JG. High potassium intake blunts the effect of elevated sodium intake on blood pressure levels. J Am Soc Hypertens. 2014;8:232-8.

20. Geleijnse JM, Kok FJ, Grobbee DE. Blood pressure response to changes in sodium and potassium intake: a metaregression analysis of randomised trials. J Hum Hypertens. 2003;17:471-80.

21. Whelton PK, Carey RM, Aronow WS, Casey DE Jr, Collins KJ, Dennison Himmelfarb C, DePalma SM, Gidding S, Jamerson KA, Jones DW, MacLaughlin EJ, Muntner P, Ovbiagele B, Smith SC Jr, Spencer CC, Stafford RS, Taler SJ, Thomas RJ, Williams KA Sr, Williamson JD, Wright JT Jr. 2017 ACC/AHA/AAPA/ABC/ACPM/AGS/APhA/ASH/ASPC/NMA/PCNA guideline for the prevention, detection, evaluation, and management of high blood pressure in adults: executive summary: a report of the American College of Cardiology/American Heart Association Task Force on Clinical Practice Guidelines. Hypertension. 2018;71:1269-324.

22. Gonzalez AA, Gallardo M, Cespedes C, Vio CP. Potassium intake prevents the induction of the renin-angiotensin system and increases medullary ACE2 and COX-2 in the kidneys of angiotensin II-dependent hypertensive rats. Front Pharmacol. 2019;10:1212.

23. Vio CP, Gallardo P, Cespedes C, Salas D, Diaz-Elizondo J, Mendez N. Dietary potassium downregulates angiotensin-I converting enzyme, renin, and angiotensin converting enzyme 2. Front Pharmacol. 2020;11:920.

24. Fujita T, Sato Y. Changes in renal and central noradrenergic activity with potassium in DOCA-salt rats. Am J Physiol. 1984;246:F670-5.

25. McCabe RD, Bakarich MA, Srivastava K, Young DB. Potassium inhibits free radical formation. Hypertension. 1994;24:77-82.

26. Matsui H, Shimosawa T, Uetake Y, Wang H, Ogura S, Kaneko T, Liu J, Ando $\mathrm{K}$, Fujita T. Protective effect of potassium against the hypertensive cardiac dysfunction: association with reactive oxygen species reduction. Hypertension. 2006;48:225-31.

27. Zucker $\mathrm{H}$, Xiao L, Haack KK. The central renin-angiotensin system and sympathetic nerve activity in chronic heart failure. Clin Sci. 2014;126:695-706.

28. Weaver CM. Potassium and health. Adv Nutr. 2013;4:368S-3775.

29. World Health Organization. Guideline: potassium intake for adults and children. Geneva: World Health Organization; 2012.

30. Bowling CB, Pitt B, Ahmed MI, Aban IB, Sanders PW, Mujib M, Campbell RC, Love TE, Aronow WS, Allman RM, Bakris GL, Ahmed A. Hypokalemia and outcomes in patients with chronic heart failure and chronic kidney disease: findings from propensity-matched studies. Cir Heart Fail. 2010;3:253-60.
31. Diaz HS, Andrade DC, Toledo C, Pereyra KV, Schwarz KG, Díaz-Jara E, Lucero C, Arce-Alvarez A, Schultz HD, Silva JN, Takakura AC, Moreira TS, Del $M N J$, Rio R. Episodic stimulation of central chemoreceptor neurons elicits disordered breathing and autonomic dysfunction in volume overload heart failure. Am J Physiol Lung Cell Mol Physiol. 2020;318:L27-40.

32. Abassi Z, Goltsman I, Karram T, Winaver J, Hoffman A. Aortocaval fistula in rat: a unique model of volume-overload congestive heart failure and cardiac hypertrophy. J Biomed Biotechnol. 2011;2011:729497.

33. Andrade DC, Toledo C, Díaz HS, Lucero C, Arce-Álvarez A, Oliveira LM Takakura AC, Moreira TS, Schultz HD, Marcus NJ, Alcayaga J, Del Rio R. Ablation of brainstem $\mathrm{C} 1$ neurons improves cardiac function in volume overload heart failure. Clin Sci. 2019:133:393-405.

34. Toledo C, Andrade DC, Díaz HS, Pereyra KV, Schwarz KG, Díaz-Jara E, Oliveira LM, Takakura AC, Moreira TS, Schultz HD, Marcus N, Del Rio R. Rostral ventrolateral medullary catecholaminergic neurones mediate irregular breathing pattern in volume overload heart failure rats. J Physiol. 2019;597:5799-820.

35. Greenwood MP, Greenwod M, Paton JFR, Murphy D. Salt appetite is reduced by a single experience of drinking hypertonic saline in the adult rat. PLoS One. 2014;9:e104802.

36. Rey S, Tarvainen MP, Karjalainen PA, Iturriaga R. Dynamic time-varying analysis of heart rate and blood pressure variability in cats exposed to short-term chronic intermittent hypoxia. Am J Physiol Regul Integr Comp Physiol. 2008;295:R28-37.

37. Marcus NJ, Del Rio R, Schultz HD. Central role of carotid body chemoreceptors in disordered breathing and cardiorenal dysfunction in chronic heart failure. Front Physiol. 2014;5:438.

38. Oliveira-Sales EB, Toward MA, Campos RR, Paton JF. Revealing the role of the autonomic nervous system in the development and maintenance of Goldblatt hypertension in rats. Auton Neurosci. 2014;183:23-9.

39. Pacher P, Nagayama T, Mukhopadhyay P, Bátkai S, Kass DA. Measurement of cardiac function using pressure-volume conductance catheter technique in mice and rats. Nat Protoc. 2008;3:1422-34.

40. Ogilvie LM, Edgett BA, Huber JS, Platt MJ, Eberl H, Lutchmedial S, Brunt KR, Simpson JA. Hemodynamic assessment of diastolic function for experimental models. Am J Physiol Heart Circ Physiol. 2020;318:H1139-58.

41. Tobian L, Lange J, Ulm K, Wold L, Iwai J. Potassium reduces cerebral hemorrhage and death rate in hypertensive rats, even when blood pressure is not lowered. Hypertension. 1985;7:110-1114.

42. Kido M, Ando K, Onozato ML, Tojo A, Yoshikawa M, Ogita T, Fujita T. Protective effect of dietary potassium against vascular injury in salt-sensitive hypertension. Hypertension. 2008;51:225-31.

43. D'Elia L, Barba G, Cappuccio FP, Strazullo P. Potassium intake, stroke, and cardiovascular disease a meta-analysis of prospective studies. J Am Coll Cardiol. 2011:57:1210-9.

44. Hunt BD, Cappuccio FP. Potassium intake and stroke risk: a review of the evidence and practical considerations for achieving a minimum target. Stroke. 2014:45:1519-22.

45. McDonough AA, Veiras LC, Guevara CA, Ralph DL. Cardiovascular benefits associated with higher dietary $\mathrm{K}+\mathrm{vs}$. lower dietary $\mathrm{Na}+$ : evidence from population and mechanistic studies. Am J Physiol Endocrinol Metab. 2017:312:E348-56.

46. Kortenoeven MLA, Esteva-Font C, Dimke H, Poulsen SB, Murali SK, Fenton RA. High dietary potassium causes ubiquitin-dependent degradation of the kidney sodium-chloride cotransporter. J Biol Chem. 2021;297:100915.

47. Veiras LC, Han J, Ralph DL, McDonough AA. Potassium supplementation prevents sodium chloride cotransporter stimulation during angiotensin II hypertension. Hypertension. 2016;68:904-12.

48. Triposkiadis F, Karayannis G, Giamouzis G, Skoularigis J, Louridas G, Butler J. The sympathetic nervous system in heart failure physiology, pathophysiology, and clinical implications. J Am Coll Cardiol. 2009;54:1747-62.

49. Llewellyn TL, Sharma NM, Zheng H, Patel KP. Effects of exercise training on SFO-mediated sympathoexcitation during chronic heart failure. Am J Physiol Heart Circ Physiol. 2014;306:H121-31.

50. Wang HW, Huang BS, White RA, Chen A, Ahmad M, Leenen FH. Mineralocorticoid and angiotensin II type 1 receptors in the subfornical organ mediate angiotensin II-induced hypothalamic reactive oxygen species and hypertension. Neuroscience. 2016;329:112-21.

51. Yoshimura R, Sato T, Kawada T, Shishido T, Inagaki M, Miyano H, Nakahara T, Mitashita H, Takaki H, Tatewaki T, Yanagiya Y, Sugimachi M, Sunagawa 
$\mathrm{K}$. Increased brain angiotensin receptor in rats with chronic high-output heart failure. J Card Fail. 2000;6:66-72.

52. Biancardi VC, Stern JE. Compromised blood-brain barrier permeability: novel mechanism by which circulating angiotensin II signals to sympathoexcitatory centres during hypertension. J Physiol. 2016;594:1591-600.

53. Campese VM, Shaohua YE, Huiquin Z. Oxidative stress mediates angiotensin II-dependent stimulation of sympathetic nerve activity. Hypertension. 2005;46:533-9.

54. Hanna IR, Taniyama Y, Szöcs K, Rocic P, Griendling KK. NAD(P)H oxidasederived reactive oxygen species as mediators of angiotensin II signaling. Antioxid Redox Signal. 2002;4:899-914.

55. Chan SHH, Hsu KS, Huang CC, Wang LL, Ou CC, Chan JYH. NADPH oxidase-derived superoxide anion mediates angiotensin ii-induced pressor effect via activation of p38 mitogen-activated protein kinase in the rostral ventrolateral medulla. Circ Res. 2005;97:772-80.

56. Giannoni A, Emdin M, Poletti R, Bramanti F, Prontera C, Piepoli M, Passino C. Clinical significance of chemosensitivity in chronic heart failure: influence on neurohormonal derangement, Cheyne-Stokes respiration and arrhythmias. Clin Sci. 2008;1 14:489-97.

57. Giannoni A, Emdin M, Bramanti F, ludice G, Francis DP, Barsotti A, Piepolo $M$, Passino C. Combined increased chemosensitivity to hypoxia and hypercapnia as a prognosticator in heart failure. J Am Coll Cardiol. 2009;53:1975-80.

58. Yamada K, Asanoi H, Ueno H, Joho S, Takagawa J, Kameyama T, Hirai T, Nozawa T, Inoue H. Role of central sympathoexcitation in enhanced hypercapnic chemosensitivity in patients with heart failure. Am Heart J. 2004;148:964-70.

59. Brack T, Thüer I, Clarenbach CF, Senn O, Noll G, Russi EW, Bloch KE. Daytime Cheyne-Stokes respiration in ambulatory patients with severe congestive heart failure is associated with increased mortality. Chest. 2007;132:1463-71.

60. Chang HY, Hu YW, Yue CSJ, Wen YW, Yeh WT, Hsu LS, Tsai SY, Pan WH. Effect of potassium-enriched salt on cardiovascular mortality and medical expenses of elderly men. Am J Clin Nutr. 2006;83:1289-96.

\section{Publisher's Note}

Springer Nature remains neutral with regard to jurisdictional claims in published maps and institutional affiliations.

Ready to submit your research? Choose BMC and benefit from:

- fast, convenient online submission

- thorough peer review by experienced researchers in your field

- rapid publication on acceptance

- support for research data, including large and complex data types

- gold Open Access which fosters wider collaboration and increased citations

- maximum visibility for your research: over $100 \mathrm{M}$ website views per year

At BMC, research is always in progress.

Learn more biomedcentral.com/submissions 